\title{
Experimental Investigation of a Displacement-controlled Hydrostatic Pump/Motor by Means of Rotating Valve Plate
}

\author{
Liselott Ericson, Samuel Kärnell, and Martin Hochwallner \\ Department of Management and Engineering, Fluid and Mechatronic Systems, Linköping University, Linköping, Sweden \\ E-mail: liselott.ericson@liu.se,samka878@student.liu.se,martin.hochwallner@liu.se
}

\begin{abstract}
Interest in the control of variable fluid power pumps/motors has increased in recent years. The actuators used are inefficient and expensive and this reduces the variable units' usability. This paper introduces displacement control of pumps/motors by means of a rotating valve plate. By changing the angle of the valve plate, the effective use of the stroke is changed. The rotating valve plate is experimentally verified by a modified in-line pump. In the prototype, the valve plate is controlled with a worm gear connected to an electric motor. The results show potential for this kind of displacement control. However, the rotating valve plate creates pressure pulsations at part-displacement due to the commutation being performed at high piston speeds. If the piston speed and hence the flow from each piston is low, the pressure pulsation is acceptable.
\end{abstract}

Keywords: Fluid power pump/motor, displacement actuator

\section{Introduction}

Interest in the control of variable fluid power pump/motor units has raised in recent years. To increase the efficiency of fluid power systems, variable machines are important. However, the displacement control actuators are considered to be unnecessarily inefficient. Also, variable machines are in general more expensive than fixed machines due to the additional control mechanism.

A summary of different displacement variations can be found in [1]. The paper concludes that variations in displacement control should require minimum actuation effort and have no negative effect on the machine's steady-state performance (efficiency, oscillation, reliability, etc.). [2] shows that the pulsating piston force acting on the swash plate causes swash plate oscillations. These oscillations cause both losses and noise issues according to Achten. In [3], three different in-line axial piston pumps were tested and their losses due to the swash-plate controller determined. The paper concludes that the main losses occur due to the constant leakage through the damping orifice.

The most common method to control the displacement of an in-line machine is to adjust the angle of the swash plate. This means that the stroke length of the pistons is varied. Control is usually purely hydraulic or electro-hydraulic. Another way to control displacement is by changing the angle of the valve plate, this means that the effective use of the stroke is varied. This displacement control is investigated in this paper.

Other research using similar concepts is described in [4], [5] and [6]. In [4], a new fluid power machine concept was presented, the Innas Hydraulic Transformer (IHT), where the valve plate has three ports. The pressure and flow are controlled by rotating the valve plate. The main issue with the concept is the difficulty with the computation zones between the ports. A large pressure build-up and cavitation occur when the land between the ports appears at other positions than piston dead centre. This problem was addressed in [7], where a shuttle valve was implemented between the ports to reduce the pressure build up and also minimise the risk of cavitation. The concept was further investigated in [8]. The papers clearly show the problem, especially at high speed where the piston speed increases the pressure build-up problem.

In [5], an original swash-plate controller is assumed to be combined with an indexing valve plate, i.e. a rotating valve plate, to reduce the self-adjusting forces and in this way reduce the force for the controllers.

In [6], valve plate rotation is used to reduce the flow pulsation produced in the pump by actively changing the position of the compression angle.

This paper presents displacement-controll of a machine by means of a rotating valve plate. By rotating the valve plate, the effective stroke is adjusted and hence the amount of flow the machine delivers per rotation. The function is verified by measurement on a modified variable in-line pump. The valve plate rotation is realised by an electric motor with a worm gear. The article amplifies problems and benefits with the rotating valve plate control. Only pump application is tested by measurements. 


\section{Concept Analysis for Rotating Valve Plate}

By rotating the valve plate the effective stroke of the machine is reduced. Due to this, the displacement can be controlled by rotating the valve plate. Figure 1 shows three different valve plate rotation angles. $\varepsilon=1$ shows the position for full pump displacement. At bottom dead centre (BDC) $\left(0^{\circ}\right)$, the piston connects to the high-pressure port and flow is pressed out from the cylinder until top dead centre (TDC) at $180^{\circ}$. At $\varepsilon=0$, the valve plate is turned $90^{\circ}$ and the piston strokes $90^{\circ}$ in the low-pressure kidney and $90^{\circ}$ in the high pressure kidney and hence no flow is moved through the machine. All angles between $0^{\circ}$ and $90^{\circ}$ produce a part flow from the pump. At angles between $90^{\circ}$ and $180^{\circ}$, the flow direction is changed and the machine works as a motor.

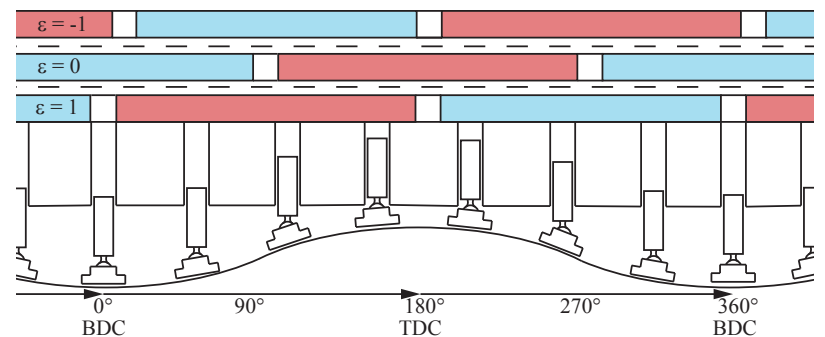

Figure 1: The valve plate location at three different locations; full pump-mode, no-flow and full motor-mode. Darker grey or red rectangles signify high-pressure port and lighter grey or blue low-pressure port.

The principle of displacement control by rotation of a valve plate in figure 1 is equivalent to swash plate control with over-centre control. The rotating valve plate can be combined with changed rotation direction and changed high- and lowpressure ports. Figure 2 shows the optimal principle design of the valve plate for a normal swash-plate controlled machine. The pre- and de-compression angles are used to equalise the pressures in the cylinders to minimise compressible flow pulsations, [9]. The feature uses the piston movement to compress the oil before connecting to the high- and lowpressure ports. In the top left figure the pre-compression angle is used to compress the oil before entering the high-pressure kidney while the de-compression angle is used to lower the cylinder pressure before connecting to the low-pressure port. The angle at bottom dead centre (BDC) is bigger because the cylinder volume is bigger at this position.

The location of the pre- and de-compression angles is important to decide the rotation direction for the different driving modes. When the valve plate is rotated, a fictive preand decompression angle is produced and hence for best circumstances, the valve plate should rotate towards the highpressure kidney. Figure 3 shows all available driving modes. In this paper only left direction of the valve plate rotation is investigated. The functionality is no different between left and right driving modes for the pump itself.

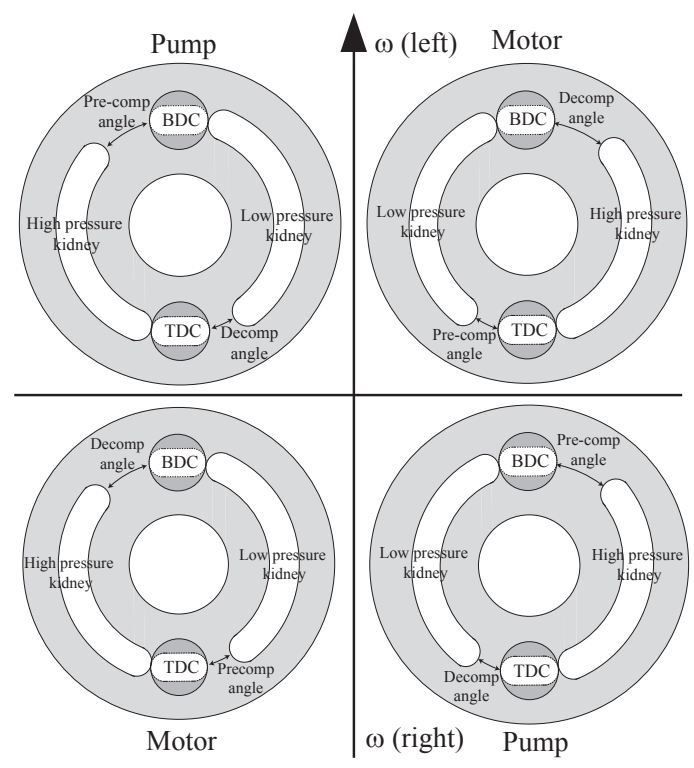

Figure 2: Principle design of optimised valve plate design for different operation quadrants for a fluid power pump/motor. The modes can be supported by a rotation valve plate to create four additional quadrants. BDC stand for Bottom Dead Centre and TDC Top Dead Centre.

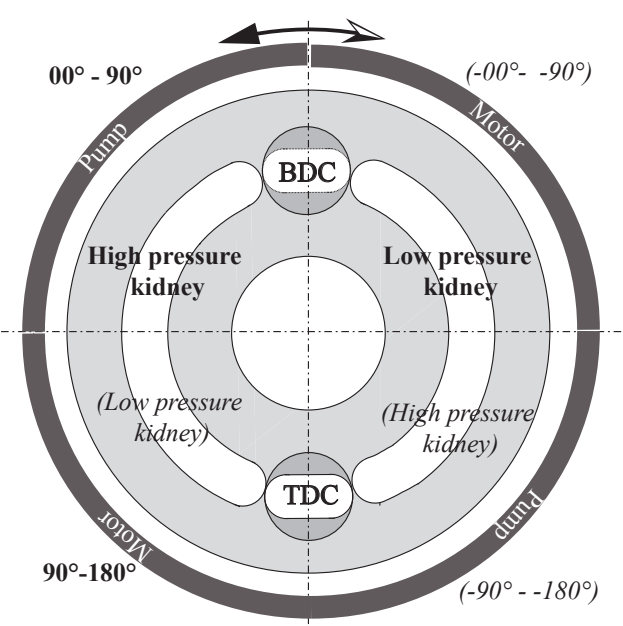

Figure 3: Rotation direction for high-pressure kidney to the right and left respectively. The valve plate should rotate towards the high pressure kidney which means negative angles is connected to the high-respective low pressure kidney in italic font.

\section{Simulation Model}

A one-dimensional simulation is used to validate the proposed controller. The model describes the flow and force pulsations in a comprehensive study of the rotational valve plate. The components are implemented with transmission line theory, TLM, see e.g. [10]. The model techniques use a distributed model structure which makes the calculations very effective due to allowableness of distributed solvers and the numerical stiffness due to the finite signal propagation speed.

The flow in one cylinder is calculated with the continuity 
equation as

$$
\sum q=\frac{\mathrm{d} V}{\mathrm{~d} t}+\frac{V_{c y l}}{\beta_{e}} \frac{\mathrm{d} p}{\mathrm{~d} t}
$$

where the last part is the cylinder capacity and represents the compressible flow. $\beta_{e}$ is the effective bulk modulus of the oil, air and container. $\frac{\mathrm{d} p}{\mathrm{~d} t}$ is the pressure change inside the cylinder while $V_{c y l}$ is the cylinder volume, which changes during barrel rotation as

$$
V_{c y l}=V_{\text {dead }}+\left(\tan \alpha_{\max }+\tan \alpha \sin \Phi\right) \tan \alpha_{\text {max }} R_{b} A_{p}
$$

The kinematic flow is modelled as the derivative of the cylinder volume as

$$
\frac{\mathrm{d} V_{c y l}}{\mathrm{~d} t}=R_{b} \tan \alpha \omega \cos \Phi A_{p}
$$

Figure 4 shows the normalised kinematic flow from one cylinder, where positive flow coming out from the cylinder and negative flow are sucked in. In figure $4 \mathrm{a}$, the valve plate has no rotation and hence the pump delivers full displacement, i.e. all flow goes into the high-pressure kidney. Figure $4 \mathrm{~b}$ shows the valve plate rotation angle at $45^{\circ}$. Only part of the flow is connected to the high-pressure kidney and hence flow is reduced.

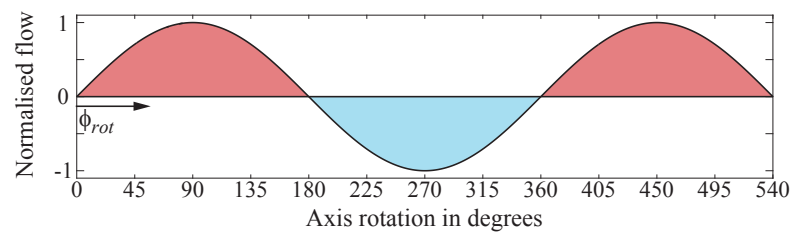

(a) Flow at zero valve plate rotation, hence full displacement.

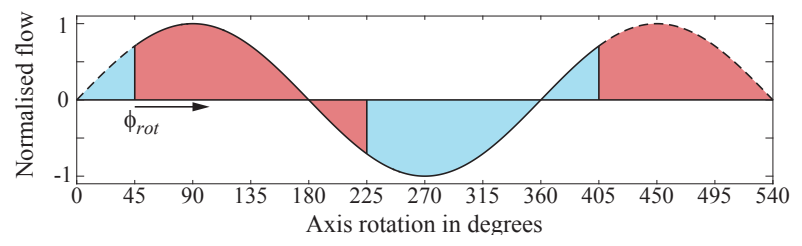

(b) Flow with $45^{\circ}$ valve plate rotation, hence $\varepsilon_{\phi}=0.7$.

Figure 4: Normalised flow from one cylinder. Light grey or blue areas are the volumes entering the cylinder from the lowpressure kidney and dark grey or red is the volume leaving the cylinder to the high-pressure kidney.

The flow from the pump depends on the rotation angle and from figure $4 \mathrm{~b}$ it can be seen that the setting ratio can be expressed as 4 . Figure 4 shows the setting ratio as a function of valve plate rotation angle.

$$
\varepsilon_{\phi}=\cos \phi_{r o t}
$$

where $\phi_{r o t}$ is the rotation angle of the valve plate.

This can be compared to the setting ratio for an original variable swash-plate pump/motor and is stated in equation (5). The angle is almost linear in the full range $-16^{\circ} \leq \alpha \leq 16^{\circ}$ as shown in figure $5 \mathrm{~b}$.

$$
\varepsilon_{\alpha}=\frac{\tan \alpha}{\tan \alpha_{\max }}
$$

$\alpha_{\max }$ is maximum displacement angle and $\alpha$ is the current displacement angle. The slow displacement change at dead

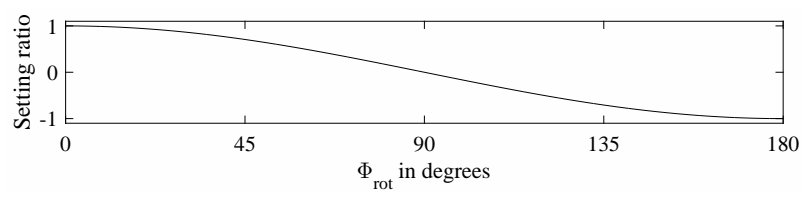

(a) Setting ratio for valve plate rotation, $\varepsilon_{\phi}$.

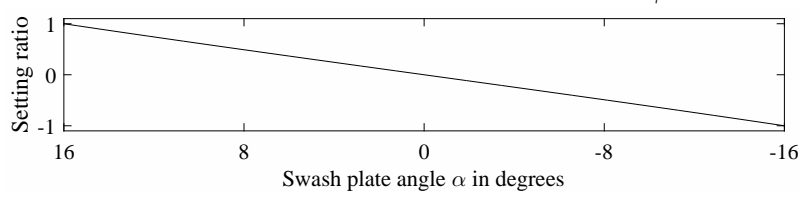

(b) Setting ratio for swash plate angle, $\varepsilon_{\alpha}$.

Figure 5: Setting ratio for valve plate rotation and swashplate tilting.

centres can be used to minimise flow pulsations at full displacements, [6].

The sum of the flow in equation (1) consists only of the flow entering or leaving the cylinder and is in this application the flow through the kidney openings. No leakage or cross-porting is considered. This restrictor is modelled with the steady state equation for a turbulence restrictor as

$$
q_{r}=C_{q} A \sqrt{\frac{2}{\rho} \Delta p_{r}}
$$

$\Delta p_{r}$ is the pressure drop over the valve, $C_{q}$ is the flow coefficient and is known to be a function of the Reynolds number and the area difference between the orifice and pipe. The value is difficult to estimate for a pump environment and the standard value for turbulent orifice 0.60 according to [11] is therefore chosen.

The restrictor opening area $A$ can be considered in different ways. Traditionally, the ports are circular and hence the opening area is modelled as the intersection between two circles, named "A" in figure 6. The opening area will be gradually opened. Another useful opening geometry is a square opening, named "B" in figure 6. This opening is faster and also linear over the full transaction area. The simulation is val-
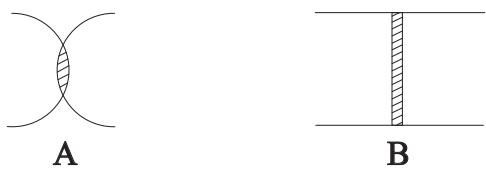

Figure 6: Two different restrictor opening geometries.

idated in earlier contributions by for example Johansson et al. [12].

\subsection{Simulation results}

Some interesting phenomena appear when the displacement is controlled by rotating of the valve plate. When using a variable in-line machine, the displacement angle can be changed. 
This allows the piston flow to be reduced, which has the benefit of reducing the pressure peak in the cylinder. In the results below, both displacement control of the swash plate angle $\alpha$ and displacement control by using the rotation valve plate $\phi_{\text {rot }}$ are used. The kidney restrictor does not open instantly and hence the cylinder volume will be compressed by the piston motion before the flow through the restrictor is bigger than the kinematic flow of the piston. Changing piston speed and hence the piston flow can be done in two ways: setting ratio by $\alpha$ or rotational speed. The two ways will have different impacts on the flow pulsation and pressure build-up in the cylinders.

Figure 7 shows the cylinder pressure at the same amount of flow but different setting ratios and rotational speeds. The graph shows how the pressure changes during a full stroke by means of valve plate rotation. The maximum cylinder pressure is reached at $\approx 90^{\circ}$, i.e. when the commutation between the cylinders is performed at maximum piston speed. The piston's linear speed in the cylinder port is the same for both curves but higher rotational speed will show smaller pressure build-up compared to higher displacement angles $(\alpha)$. By changing the flow with rotational speed the restrictor opening rate will also change, which means that the pressure buildup will be smaller if the flow is increased by rotational speed compared to displacement angle.

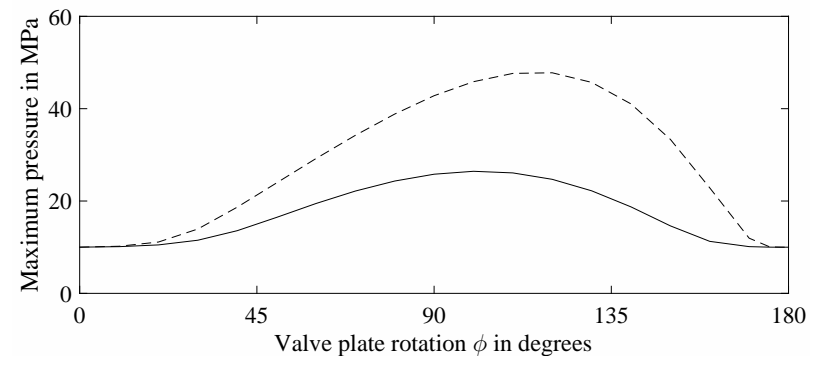

Figure 7: Maximum cylinder pressure at same flow and same piston speed but different rotational speed and displacement angles. Solid line shows 2000 rpm with setting ratio 0.4 and dashed line shows 1000 rpm with setting ratio 0.8.

In figure 8, the speed dependency is amplified. In the figure, the opening area and cylinder pressure build-up are shown. The opening rate is increased by the rotational speed but the flow is also increased and hence the flow rate is increased more than the opening rate and the increased pressure rate is a fact. The pressure build-up is reduced by the compressible part of equation (1).

The pressure build-up depends on the continuity equation. If the flow is decreased, the pressure build-up will be reduced. The compressible part of the equation will damp the pressure build-up. Figure 9 shows the cylinder pressure and the corresponding flow pulsation amplitude as

$$
\Delta q_{H}=\max \left(q_{H}\right)-\min \left(q_{H}\right)
$$

where $q_{H}$ is the flow in the high pressure kidney.

The flow pulsation amplitude is first reduced due to changed pre-compression of the cylinder volume and when the flow

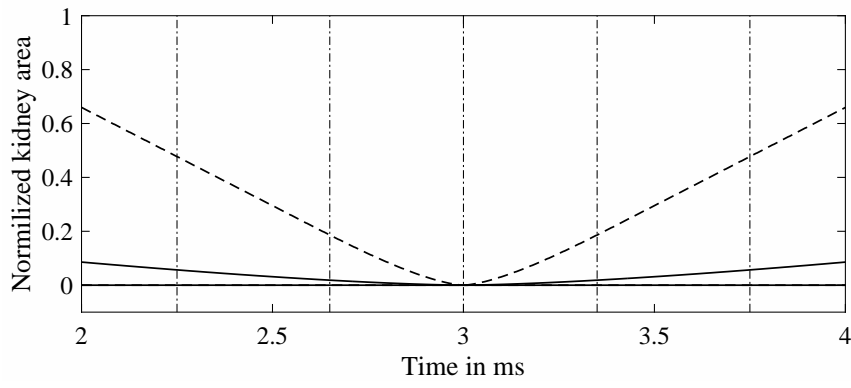

(a) Kidney opening area as a function of time.

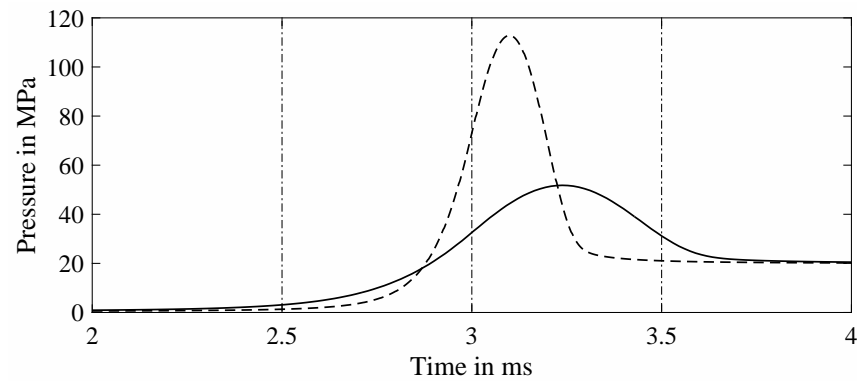

(b) The cylinder pressure in the commutation zone between low-and high-pressure kidney.

Figure 8: Differences between different rotational speeds when the valve plate rotation angle $\neq 0$. Dashed line shows $5000 \mathrm{rpm}$ and solid line shows $1000 \mathrm{rpm}$.

is decreased by valve plate rotation the flow amplitude increases. The maximum cylinder pressure decreases with setting ratio and a reasonable amplitude is reach at $\varepsilon_{\alpha} \approx 0.4$. The flow pulsation is also fair here.

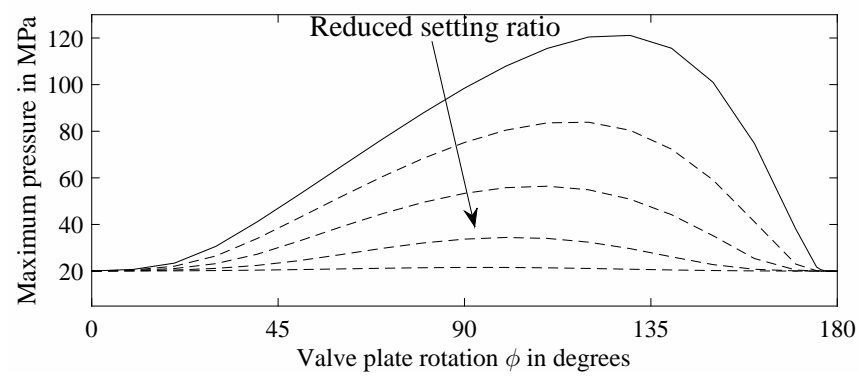

(a) Maximum cylinder pressure as function of valve plate rotation.

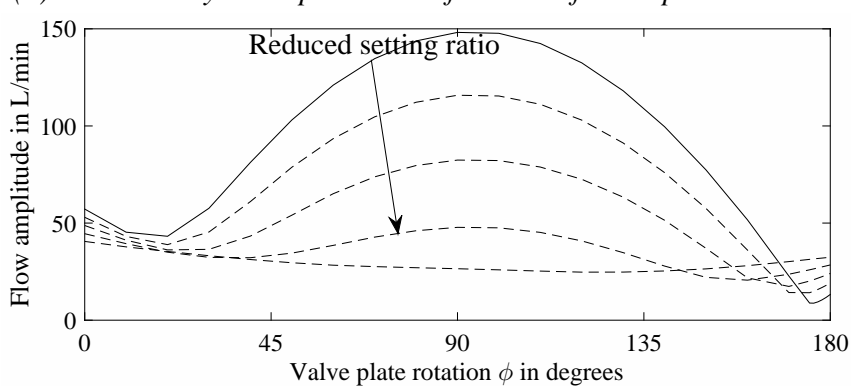

(b) Flow pulsation amplitude as function of valve plate rotation.

Figure 9: Results at 200 bar and 3000 rpm at different setting ratios, i.e. different piston velocities. The restrictor is modelled as circles. Solid line shows full displacement and the other curves show decreased setting ratio with steps of 0.2. 
Figure 10 shows different speeds in combination with different pressure levels at $\varepsilon_{\alpha}=0.4$. The cylinder pressure buildup is larger than the port pressure decreases with increased pressure level due to the compressible part of equation (1). Increased speed will cause a larger pressure build-up as explained earlier.

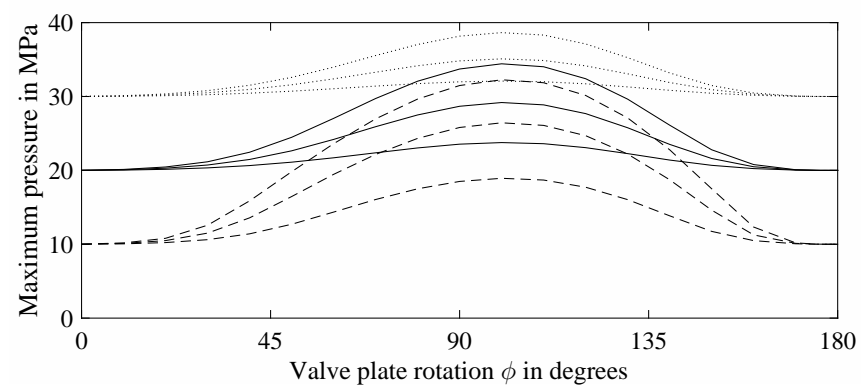

(a) Maximum cylinder pressure as a function of valve plate rotation.

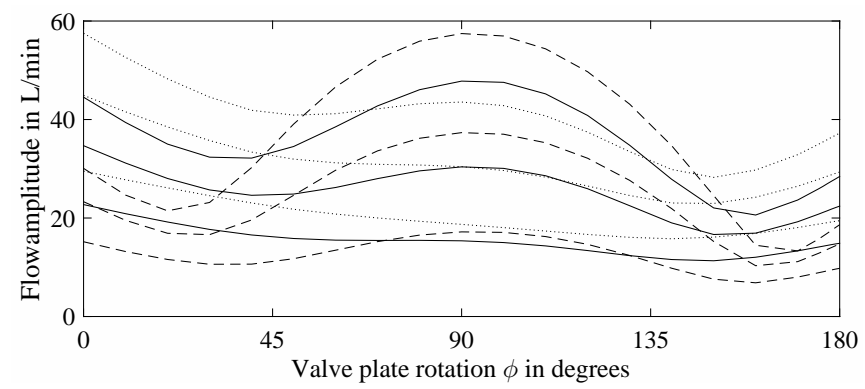

(b) Flow pulsation amplitude as a function of valve plate rotation.

Figure 10: Results at different rotational speeds and pressure levels at setting ratio 0.4. Dashed lines show 100 bar, solid lines show 200 bar and dotted lines show 300 bar. The different lines at the pressure level are $1000 \mathrm{rpm}, 2000 \mathrm{rpm}$ and 3000 rpm from below.

To additionally reduce the cylinder pressure build-up a square opening can be used, named "B" in figure 6. This is shown in figure 11 and should be compared to figure 9. The cylinder pressure is then reduced by $\approx 50 \%$.

\section{Hardware Design}

The application used is a variable in-line pump with important parameters as shown in table 1 . One quadrant operation is tested. To reduce the pressure build-up the setting ratio is set to $\varepsilon_{\alpha}=0.5$ in all tests and the rotation speed is limited to 1500 rpm. The restrictor has a circular design with a zero lapped valve plate, i.e. when one kidney is just completely closed, the next kidney will start to open up. The pump is variable

\begin{tabular}{llll}
\hline Variable & Description & Value & Unit \\
\hline$D_{p}$ & Displacement & 60 & $\mathrm{~cm}^{3} / \mathrm{rev}$ \\
$\alpha_{\text {max }}$ & Displacement angle & 16 & $\mathrm{deg}$ \\
$\varepsilon_{\alpha}$ & Setting ratio & 0.5 & - \\
\hline
\end{tabular}

Table 1: Parameters for the variable in-line pump used.

with a constant pressure controller. The pressure is set to a

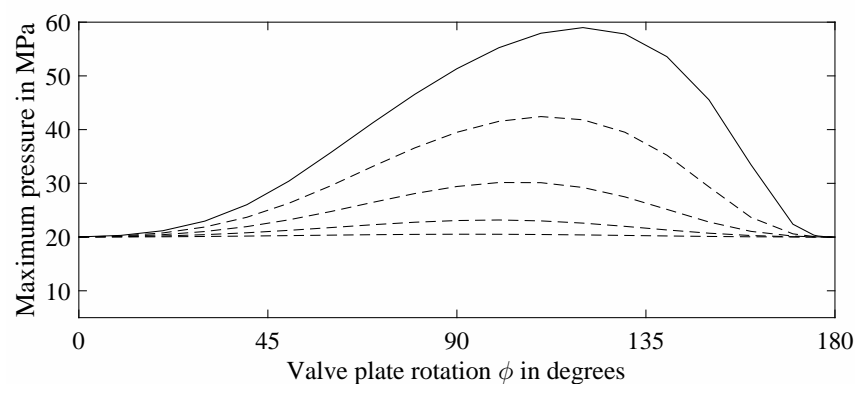

(a) Maximum cylinder pressure as a function of valve plate rotation.

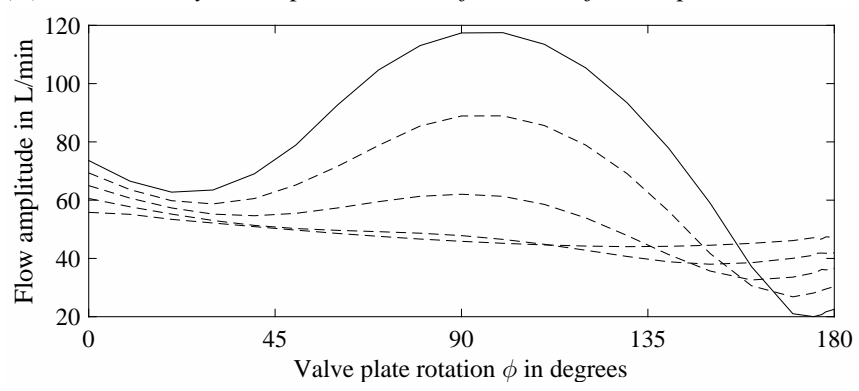

(b) Flow pulsation amplitude as a function of valve plate rotation.

Figure 11: Results at 200 bar and 3000 rpm at different setting ratios, i.e. different piston velocities. The restrictor is modelled as square. Solid line shows full displacement and the other curves show decreased setting ratio with steps of 0.2 .

larger pressure than used in the system however, and hence the pump is displaced to the maximum setting angle at all times. The benefit of using a variable pump is that the maximum displacement angle can be set to an appropriate value. Figure 12 shows the tested machine.

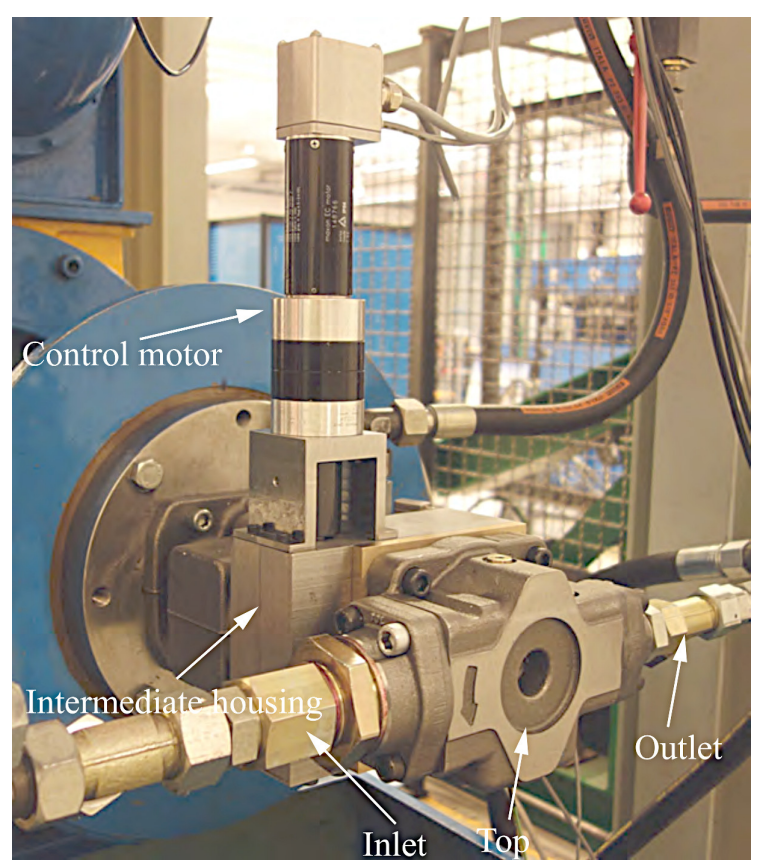

Figure 12: The final pump design mounted on the test rig. 


\subsection{Mechanical construction}

There are two obvious methods to control the flow to the correct port in the radial sliding ring method, where the kidneys connect to the port radially, the channels become rather narrow and expected to be long. The other method is axial connection, where the channels of the valve plate are extended and the connection between the valve plate and the ports is made axially. The rotating valve plate is balanced with hydrostatic bearings. The tested pump is designed with an axial connection system. The first prototype was designed as a student project at Linköping University in autumn 2016, [13]. This prototype has since been updated.

Figure 13 shows all the parts of the rotating valve plate. It is designed to not have any impact on the original pump and hence the pump can be tested both as original and with the rotating valve plate control. The design consists of a worm gear (Worm wheel and Worm screw) connected to a brush-less DC-motor (Control motor). On the either side of the worm wheel, adapters (Adapter 1 and Adapter 2) are made to direct the flow. These parts can be seen as an extension of the valve plate and are made out of several parts for manufacturing reasons. The original valve plate is mounted on adapter 1 . The top extension is made to increase the size of the possible rotation angle and is also made in a bronze kind material for better sliding behaviour of the rotating valve plate. Figure 14 shows

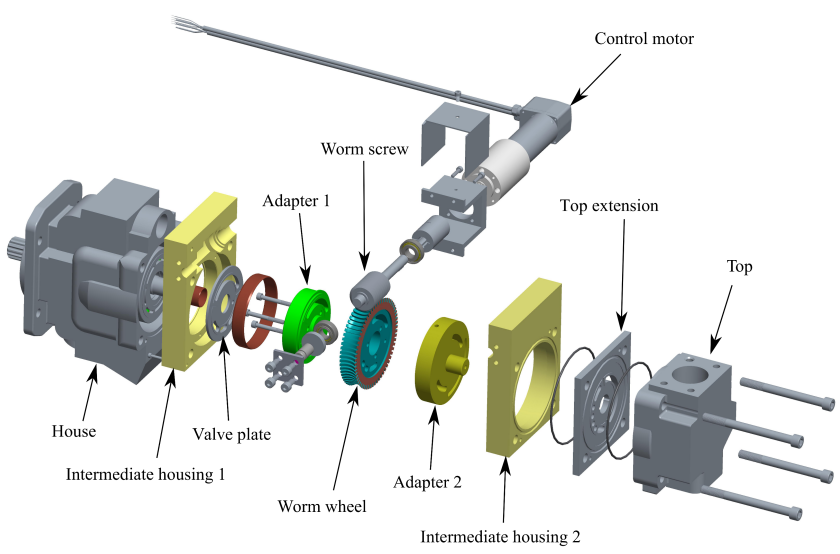

Figure 13: The mechanical design of the prototype. The top and housing are unchanged from original pump.

the working principle applied on the mechanical design. Adapter 1 , the worm wheel and adapter 2 are called a rotating drum. The valve plate is fixed connected to this drum. The valve plate and drum are the parts which rotate. The kidneys are reduced in length at the connection to the top extension. The possible rotation angle is mechanically restricted to the range between $-5^{\circ}$ and $99^{\circ}$, and a full pump stroke can be tested.

\subsection{Drive of valve plate}

The worm screw is driven by a brush-less DC-motor with planetary gear head, encoder and hall-sensors, which is connected to a motor controller. A MyRIO is used as the main controller hardware. MyRIO features a real-time processor

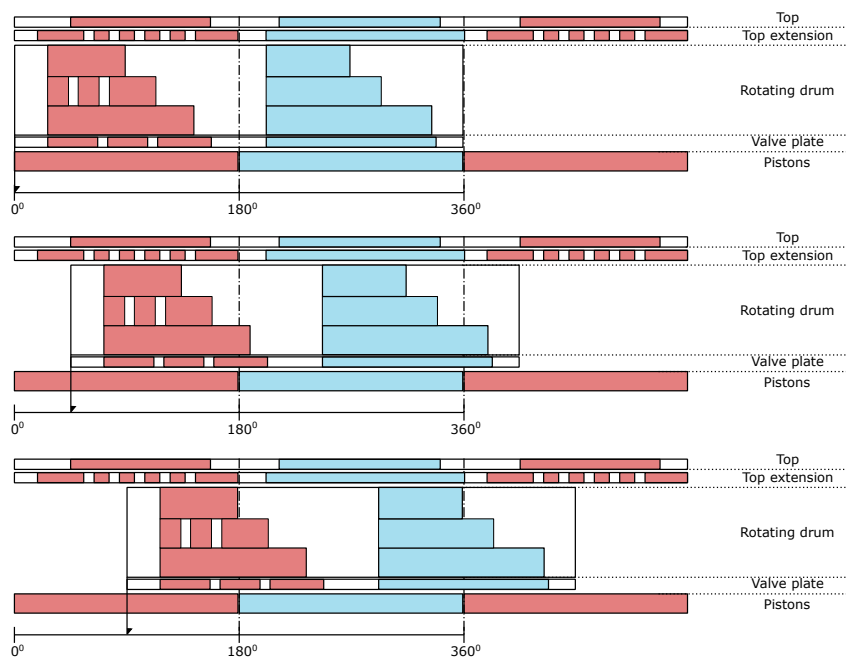

Figure 14: The construction in a linear view of the different layers in the design. In the bottom layer, the barrel and pistons are shown. The valve plate and drum are the rotating part. The top picture shows full displacement, the full stroke and hence all flow goes to the high-pressure kidney. The middle figure shows when the setting ratio is $\varepsilon_{\phi}=0.7$ and the bottom when no flow is delivered.

and an FPGA, whereby both are programmed in LabVIEW. Both the motor controller and MyRIO, use the encoder signals from the motor, whereby the motor controller realises speed control and the position controller is implemented in MyRIO. The motor controller provides a signal corresponding to the motor current which is used to estimate the motor torque.

The accuracy of the valve plate angle measurement is dominated by the stiffness of the gear head and most of all the play in the home-made worm gear. The play in the worm gear is small.

The parameters of the drive are shown in table 2. With the stated maximum speed and gear ratio, the setting time from $\varepsilon_{\phi}=0$ to 1 is approximately $1.8 \mathrm{~s}$.

\begin{tabular}{llll}
\hline Variable & Discription & Value & Unit \\
\hline$i$ & Total gear ratio & 1191 & - \\
$n_{c m}$ & Speed continuous & 10000 & $\mathrm{rpm}$ \\
$T_{c o n}$ & Torque continuous & 316 & $\mathrm{Nm}$ \\
\hline
\end{tabular}

Table 2: Parameters of the valve plate drive.

\section{Test Set-up}

Figure 15 shows the test set-up. The pump is driven by a 90 $\mathrm{kW}$ DC-motor. The pump is connected directly to an electrically controlled pressure relief valve. Outlet and inlet flow and pressures are measured as well as the rotational speed of the drive motor. The pump's inlet is pressurised to prevent cavitation. The current and position are measured at the control motor. The position is judged as the position of the valve plate 
rotation. The current is used to calculate the torque needed to control the valve plate. All measurement is made at $\varepsilon_{\alpha}=0.5$.

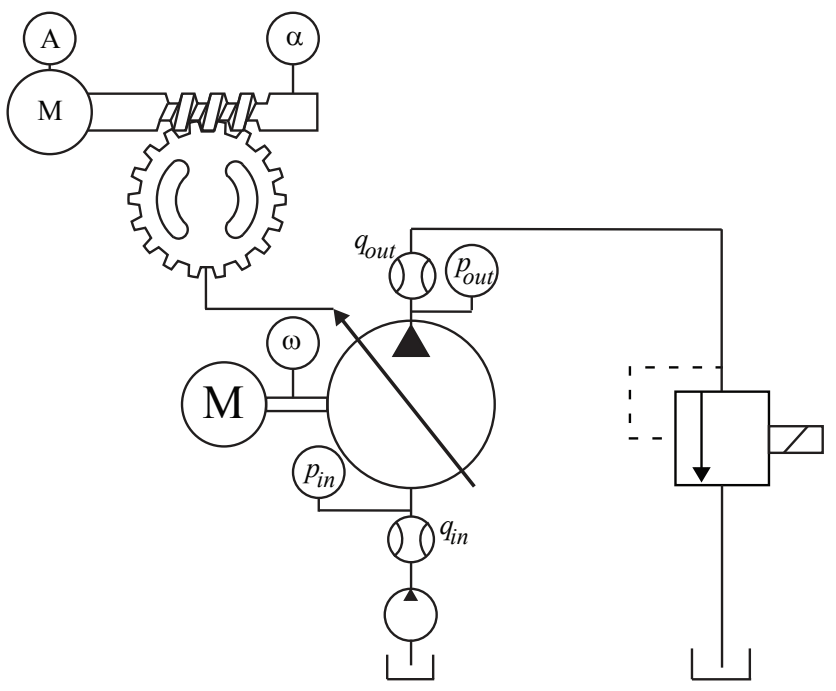

Figure 15: Set-up for testing the displacement-controlled pump with a rotating valve plate. The figure shows the transducers used.

This is done to reduce the maximum cylinder pressure.

\section{Results}

Equation (4) is verified with figure 16. Theoretical value of $\varepsilon_{\phi}$ is shown with the measured normalised flow. The losses have been taken out from the flow calculations.

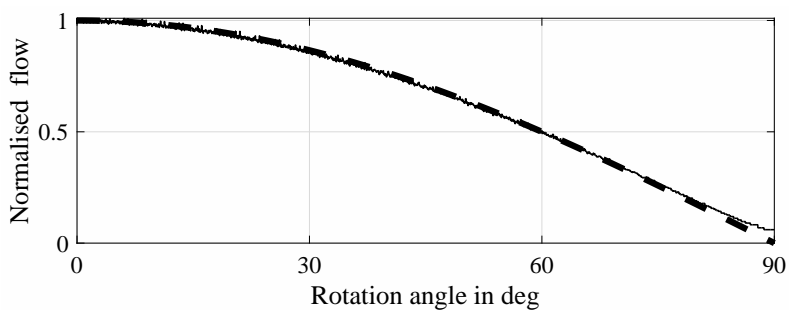

Figure 16: The flow characteristics of the displacementcontrolled pump. Thick dashed line is the theoretical value of $\varepsilon_{\phi}$ while the solid line is the measured flow. The deviation at rotation angles $>80$ degrees may be caused by inaccuracy of the flow meter.

Figure 17 shows the flow at step response measurements. The theoretical flow at rotational speed of $750 \mathrm{rpm}$ and maximum displacement $30 \mathrm{~cm}^{3} / \mathrm{rev}$ is $22.5 \mathrm{~L} / \mathrm{min}$, which means the volumetric efficiency is $\approx 0.8$. The pressure difference over the pump is here just $2.5 \mathrm{MPa}$.

Figure 18 shows the response for different pressure levels and step sizes. The full setting time is $1.8 \mathrm{sec}$. The main limitation of the step time is the maximum rotational speed of the control motor.

The torque of the control motor is shown in figure 19. When the motor accelerates full continuous torque is used. The torque peaks which are seen at bigger rotational angles than

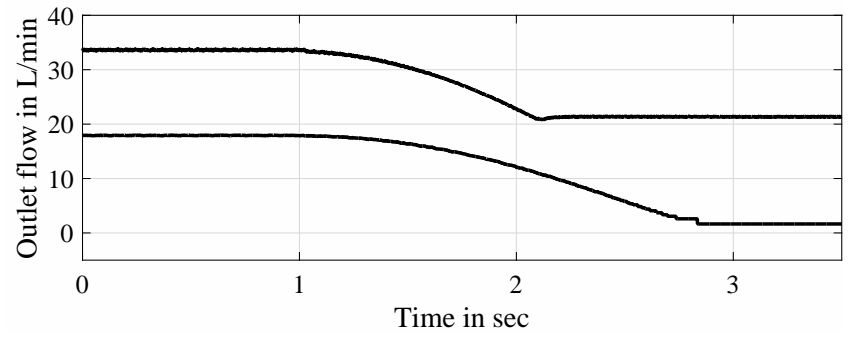

Figure 17: Flow at 750 rpm and $1500 \mathrm{rpm}$ with a step of $90^{\circ}$ and $50^{\circ}$ respectively. The pressure increase over the pump for the $750 \mathrm{rpm}$ curve is $1 \mathrm{MPa}$ and for $1500 \mathrm{rpm} 2.5 \mathrm{MPa}$.

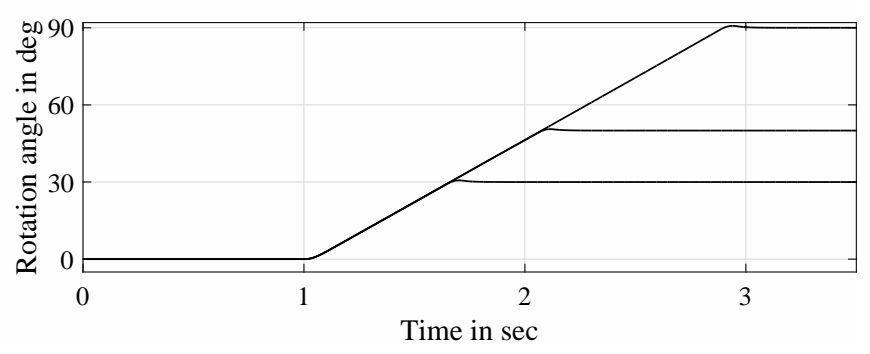

(a) The setting ratio is decreased.

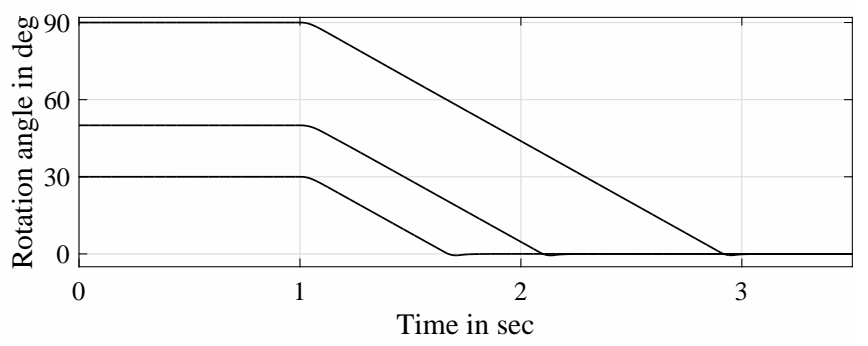

(b) The setting ratio is increased.

Figure 18: Step responses at displacement stroke of $30^{\circ}, 50^{\circ}$ and $90^{\circ}$. The pressure and rotational speed are different between the steps.

$45^{\circ}$ have the frequency of the teeth of the worm gear. This is most probably caused by the design and its tolerances.

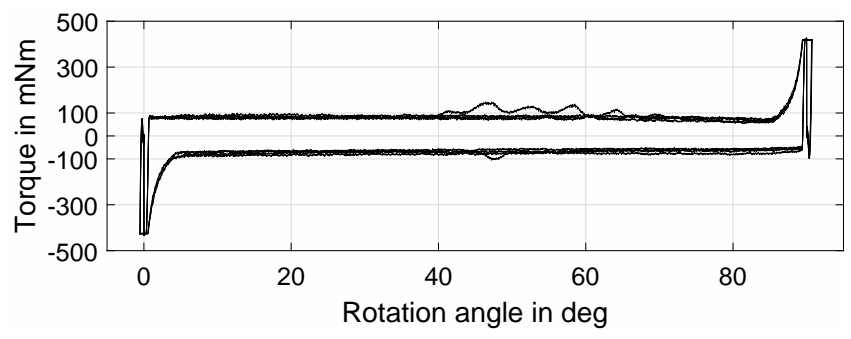

Figure 19: The torque at the full stroke step responses at different rotational speeds (750 rpm and $1500 \mathrm{rpm}$ ) and pressures 0.2-8 MPa. The positive values are when the setting ratio is increased while the negative values are at a decreasing setting ratio. 


\section{Discussion}

A simulation model used to investigate the flow pulsation created when the valve plate rotates. The pressure pulsation is worst at smallest displacement setting ratio, i.e. when the commutation is made when the piston has maximum speed. This will be an issue when controlling the displacement by rotating valve plate. This was also found by [7] who tried to reduce the issue by means of shuttle valves. It can be reduced by implementing square ports.

Displacement control by rotating valve plate is verified with the pump prototype. The flow follows the theoretical value. Volumetric efficiency is poor due to insufficient manufacturing quality. The hydrostatic bearing between the rotating valve plate and housing is over-balanced. The leakage can be reduced by decreasing the sealing areas between drum and top extension. For larger rotations, i.e. for over-centre control, radial port location is probably a necessity.

The setting time is long due to the high gear ratio implemented. The setting torque is about $0.1 \mathrm{Nm}$ while the maximum continuous torque is $0.3 \mathrm{Nm}$. The torque is almost independent of the rotation direction and pressure level.

The main setting time is caused by the limited rotational speed. The setting time can be reduced approximately three times by decreasing of the gear ratio between the control motor and the valve plate. The new setting time will be $0.6 \mathrm{sec}$, which is a more realistic time for many applications. The setting time can be reduced further by increasing the power of the electric motor or an electro-hydraulic solution. The power needed is still small compared to swash-plate actuator forces.

\section{Conclusions}

The article shows an experimental verification of displacement control by means of rotating valve plate. An in-line axial piston pump is modified so that the valve plate can be rotated by an external electric motor. The displacement setting time for the prototype is rather slow and the volumetric efficiency is low. However, this is not limited by the principle of the rotating valve plate as such. The pressure pulsation and hence the noise level may be an issue but with correct design and low piston speeds, the noise problem can be handled.

\section{Acknowledgement}

This research was partially funded by the Swedish Energy Agency (Energimyndigheten).

\section{Nomenclature}

\begin{tabular}{lll}
\hline Designation & Denotation & Unit \\
\hline$q$ & Flow & $\mathrm{m}^{3} / \mathrm{s}$ \\
$\alpha$ & Displacement angle & $\mathrm{deg}$ \\
$\alpha_{\max }$ & Maximum displacement angle & $\mathrm{deg}$ \\
$V_{c y l}$ & Cylinder volume & $\mathrm{m}^{3}$ \\
$\beta_{e}$ & Effective bulk modulus & $\mathrm{Pa}$ \\
$p$ & Pressure & $\mathrm{Pa}$ \\
$V_{\text {dead }}$ & Cylinder dead volume & $\mathrm{m}^{3}$ \\
$\Phi$ & Barrel rotation & $\mathrm{deg}$ \\
$A_{p}$ & Piston area & $\mathrm{m}^{2}$ \\
$R_{b}$ & Barrel radius & $\mathrm{m}$ \\
$\phi_{\text {rot }}$ & Valve plate rotation & $\mathrm{deg}^{3}$ \\
$q_{H}$ & Flow in high pressure port & $\mathrm{m}^{3} / \mathrm{s}$ \\
$\varepsilon_{\phi}$ & Setting ratio valve plate rotation & $\mathrm{deg}$ \\
$\varepsilon_{\alpha}$ & Setting ratio swash plate & $\mathrm{deg}$ \\
\hline
\end{tabular}

\section{References}

[1] Karl Hartmann and Ludger Frerichs. Development of innovative solutions for displacement variation in hydrostatic machines. In 10th International Fluid Power Conference, volume 1, pages 427-440, 2016.

[2] P Achten. Dynamic high-frequency behaviour of the swash plate in a variable displacement axial piston pump. Institution of Mechanical Engineers, Part I: Journal of Systems and Control Engineering published, 227(6):1-12, June 2013.

[3] Jan Lux and Hubertus Murrenhoff. Experimental loss analysis of displacement controlled pumps. In 10th International Fluid Power Conference (10. IFK), Dresden, Germany, March 8 - 102016.

[4] P Achten, Z Fu, and G Vael. Transformer future hydraulics: a new design of a hydraulic transformer. In Proc. of The 5th Scandinavian International Conference on Fluid Power, SICFP'97, Tampere, Finland, May 2123 1997. CD.

[5] Junhee Cho, Xiaoping Zhang, Noah D. Manring, and Satish S. Nair. Dynamic modelling and parametric studies of an indexing valve plate pump. International Journal of Fluid Power, 3(3):37-48, 2002.

[6] T Grahl. Geräuschminderung an axialkolbenpumpen durch variable umsteuersysteme. $O+P$, Ölhydraulik und Pneumatik, 5:437-443, November 1989.

[7] Peter A.J. Achten and Georges E.M. Vael. 'shuttle' technology for noise reduction and efficiency improvement of hydrostatic machines. In Proc. of The 7th Scandinavian International Conference on Fluid Power, SICFP'01, Linköping, Sweden, May 28-30 2001.

[8] A Johansson, R Werndin, and J-O Palmberg. Dynamic analysis of shuttle technique performance applied on hydraulic transformer. In Proc. of 3rd International Fluid Power Conference, IFK'3, volume 2, pages 249-261. Aachen, Germany, March 2002. 
[9] K A Edge and J Darling. A theoretical model of axial piston pump flow ripple. Journal of Institution of Mechanical Engineers, 200(B1):45-54, September 1986.

[10] P Krus, A Jansson, J-O Palmberg, and K Weddfelt. Distributed simulation of hydromechanical systems. In Proc. of 3rd Bath International Fluid Power Workshop, Bath, UK, September 13-14 1990.

[11] H E Merritt. Hydraulic Control Systems. John Wileys and Sons, Cincinnati, Ohio, 1967. ISBN 0-471-596175 .

[12] A Johansson, J Ölvander, and J-O Palmberg. Experimental verification of cross-angle for noise reduction in hydraulic piston pumps. Journal of Institution of Mechanical Engineers, Part I: J. Systems and Control Engineering, 221(I3):pp. 321-330, 2007.

[13] Emil Lindborg, Emma Sandström, Karin Gustafsson, Samuel Kärnell, Simon Ward, and Vincent Liljeholm. Displacement and pulsation control by implementation of a rotatable valve plate on a hydraulic piston pump. Technical report, Fluid and Mechatronic Systems, Department of Management and Engineering, Linköping Universiity, 2016. LIU-IEI-RR-16/00260-SE, Supervisors: Liselott Ericson and Martin Hochwallner. 